\title{
The Effect of Concussive Injury on Individual Game Performance in Professional Collision-Sport Athletes
}

\author{
Corey P. Ochs, Melissa C. Kay, and Johna K. Register-Mihalik
}

\begin{abstract}
Clinical Scenario: Collision sports are often at higher risk of concussion due to the physical nature and style of play. Typically, initial clinical recovery occurs within 7 to 10 days; however, even this time frame may result in significant time lost from play. Little has been done in previous research to analyze how individual game performance may be affected upon return to play postconcussion. Focused Clinical Question: Upon return-to-play clearance, how does sport-related concussion affect game performance of professional athletes in collision sports? Summary of Key Findings: All 3 studies included found no significant change in individual performance of professional collision-sport athletes upon returning to play from concussive injury. One of the studies indicated that there was no difference in performance for NFL athletes who did not miss a single game (returned within $7 \mathrm{~d}$ ) and those who missed at least 1 game. One study indicated that although there was no change in performance of NFL players upon returning to play from sustained concussion, there was a decline in performance in the 2 weeks before the diagnosed injury and appearing on the injury report. The final study indicated that there was no difference in performance or style of play of NHL athletes who missed time due to concussive injury when compared with athletes who missed games for a noninjury factor. Clinical Bottom Line: There was no change in performance upon return from concussive injury suggesting that players appear to be acutely recovered from the respective concussion before returning to play. This suggests that current policies and management properly evaluate and treat concussed athletes of these professional sports. Strength of Recommendation: Grade C evidence exists that there is no change in individual game performance in professional collision-sport athletes before and after suffering a concussion.
\end{abstract}

Keywords: brain concussion, physical performance, recovery, return to play

\section{Clinical Scenario}

Concussions are one of the most common sports-related injuries affecting athletes of all ages. Collision sports, such as football and ice hockey, are often at a higher risk of concussion due to the physical nature and style of play. Incidence ranges from 6.61/1000 athlete exposures in football ${ }^{1}$ to $1.55 / 1000$ athlete exposures in ice hockey. ${ }^{2}$ Professional sports leagues, such as the National Football League (NFL) and National Hockey League (NHL), have instituted policies to assess and manage concussions, including return to play; however, little is known about the resulting time out of play and the potential athletic consequences following this time loss. Concussions in professional sports, such as football and ice hockey, are unique due to players' job security relying on their ability to perform. Typically, initial clinical recovery occurs within 7 to 10 days $^{3}$; however, even this time frame may result in significant time lost from game and practice play. Although there has been a significant amount of research into neurocognitive and neurophysiological changes in professional athletes after a concussion, little has been done to analyze how individual game performance may be affected on return to play. Therefore, the purpose of this review was to examine postconcussion game performance within professional-level football and ice hockey players.

The authors are with the Department of Exercise and Sport Science, University of North Carolina at Chapel Hill, Chapel Hill, NC. Kay (mkay@email.unc.edu) is corresponding author.

\section{Focused Clinical Question}

Upon return-to-play clearance, how does sport-related concussion affect game performance of professional athletes in collision sports?

\section{Summary of Search, "Best Evidence" Appraised, and Key Findings}

- The literature search was limited to articles that were level 3 evidence or higher, investigated the effect of concussions on individual performance of professional-level collision-sport athletes, written in English, and published within the last 5 years.

- The literature search produced 3 possible studies (1 case-control study, 1 retrospective cohort study, and 1 cohort study). ${ }^{4-6}$

- Two of the studies investigated performance of athletes in the $\mathrm{NFL}^{4,5}$ and 1 study investigated performance of athletes in the NHL. ${ }^{6}$

- All 3 studies included found no significant change in individual performance of professional collision-sport athletes upon returning to play from concussive injury. ${ }^{4-6}$

- One of the studies indicated that there was no difference in performance for NFL athletes who did not miss a single game (returned within $7 \mathrm{~d}$ ) and those who missed at least 1 game. $^{4}$

- One study indicated that although there was no change in performance of NFL players upon returning to play from sustained concussion, there was a decline in performance in 
the 2 weeks before the diagnosed injury and appearing on the injury report. ${ }^{5}$

- One study indicated that there was no difference in performance or style of play of NHL athletes who missed time due to concussive injury when compared with athletes who missed games for a noninjury factor. ${ }^{6}$

\section{Clinical Bottom Line}

Concussive injuries impact athletes of all ages, including those at professional levels. Athletes of professional collision sports are especially susceptible to concussion and therefore miss time due to removal from play; however, evidence shows that there is no change in performance in their respective sport upon return to play for these athletes. In both NFL and NHL players, there was no change in performance upon return from concussive injury suggesting that players appear to at least acutely recover from concussion before returning to play. This suggests that current policies and management properly evaluate, treat, and safely return concussed athletes of these professional sports to the playing field. Additional research is needed to better evaluate the effect of concussions on performance, including using different metrics for performance and focusing on different types of athletes and longer time frames postinjury.

\section{Strength of Recommendation}

Grade $\mathrm{C}$ evidence exists that there is no change in individual game performance in professional collision-sport athletes before and after suffering a concussion.

\section{Search Strategy}

\section{Terms Used to Guide Search Strategy}

- Patient/Client Group: professional athletes, collision sports, football, hockey

- Intervention (or Assessment): concussion

- Comparison: not applicable

- Outcome(s): performance statistics, player impact, athlete/ returning/game performance, individual performance

\section{Sources of Evidence Searched}

- The Cochrane Library

- MEDLINE

- CINAHL

- SPORTDiscus

- Additional resources obtained via review of reference lists and hand search

\section{Inclusion and Exclusion Criteria}

\section{Inclusion}

- Level 3 evidence or higher

- Studies that investigated postconcussion game performance in collision sports

- Limited to the English language

- Limited to the past 5 years

\section{Exclusion}

- Studies that included noncollision sports

- Studies of Australian rules football

\section{Results of Search}

Three relevant studies ${ }^{4-6}$ were located and categorized as shown in Table 1 (based on Levels of Evidence, Centre for Evidence Based Medicine). ${ }^{7}$

\section{Best Evidence}

The following studies were identified as the "best" evidence and selected for inclusion in the critically appraised topic. See Table 2 for the summary of best evidence. Reasons for selecting these studies were as follows:

- They all contained level of evidence 3 or higher

- They all analyzed effects of concussive injury on individual performance of professional-level collision-sport athletes

\section{Implications for Practice, Education, and Future Research}

All 3 studies reviewed and examined the effect of concussions on performance of professional collision-sport athletes upon return to play. ${ }^{4-6}$ Two of the studies examined the performance of professional football players, ${ }^{4,5}$ whereas the other study examined the performance of professional hockey players. ${ }^{6}$ One of the NFL studies analyzed performance through ProFootballFocus scores, ${ }^{4}$ and the other used defense-adjusted yards against replacement as a performance metric. ${ }^{5}$ The NHL study used many individual game statistics to define overall performance and style of play. ${ }^{6}$ All 3 studies generally showed no change in performance for athletes of these collision sports after sustaining a concussion and returning to play. ${ }^{4-6}$

This lack of change in performance for professional athletes may signal that proper diagnosis and management of concussion are occurring before allowing the athletes to return to play. However, it is also important to note that the methods used in these studies to measure performance may not be adequate to detect adverse effects caused by concussion on the performance of these athletes. In addition, the studies were relatively short term. Concussion is a nuanced and complicated injury, and the performance metrics used in these studies may have been too broadly encompassing to detect the slight changes in performance that the

\section{Table 1 Summary of Study Designs of Articles Retrieved}

\begin{tabular}{llcl}
\hline Level of & $\begin{array}{l}\text { Study design/ } \\
\text { methodology } \\
\text { ef articles } \\
\text { retrieved }\end{array}$ & $\begin{array}{l}\text { Number } \\
\text { located }\end{array}$ & Author \\
\hline 3 & $\begin{array}{l}\text { Case-control study } \\
\text { Retrospective } \\
\text { cohort study }\end{array}$ & 1 & Kumar et al $^{4}$ \\
3 & Cohort study & 3 & Reams et al $^{5}$ \\
3 & & 3 & Kuhn et al $^{6}$ \\
\hline
\end{tabular}


Table 2 Characteristics of Included Studies

\begin{tabular}{|c|c|c|}
\hline & Study $1-$ Kumar et al ${ }^{4}$ & Study 2 -Reams et al ${ }^{5}$ \\
\hline Study design & Case-control study & Retrospective cohort study \\
\hline Participants & $\begin{array}{l}\text { - NFL players active from } 2008 \text { to } \\
2012 \text {. } \\
\text { - Inclusion criteria: players listed on } \\
\text { injury reports with a concussion or } \\
\text { head injury, players that played in } \\
\text { at least } 4 \text { games before and after the } \\
\text { game of injury in the year of injury. } \\
\text { - Exclusion criteria: players who } \\
\text { missed games in the injury year } \\
\text { due to other injury, players who } \\
\text { sustained a second concussion } \\
\text { within the year of injury. } \\
\text { - A total of } 124 \text { players with } 131 \\
\text { concussions met the inclusion and } \\
\text { exclusion criteria. }\end{array}$ & $\begin{array}{l}\text { - NFL skill position players with at } \\
\text { least } 1 \text { live touch in regular season } \\
\text { play from } 2007 \text { to } 2010 \text {. } \\
\text { - Inclusion criteria: players with } \\
\text { sustained concussion or head } \\
\text { injury as listed on injury reports, } \\
\text { players with other injuries of the } \\
\text { head or neck were designated as } \\
\text { controls. } \\
\text { - Exclusion criteria: players with } \\
\text { multiple injuries listed on the injury } \\
\text { report. } \\
\text { - A total of } 140 \text { concussions and } 57 \\
\text { controls met the inclusion and } \\
\text { exclusion criteria. }\end{array}$ \\
\hline
\end{tabular}

Intervention investigated

Outcome measure(s)
- Performance was measured using player ratings determined by PFF.

- History of prior concussion was determined from previous injury reports.

- Other variables collected included: age, position played, career games played, career years played, plays per game (snaps), and games missed due to injury.

- BMI for each player was calculated according to current information in NFL profile.

- PFF scores are position-specific measures of individual performance per game. They use position-related metrics and are unrelated to play outcome or performance of teammates or opponents. Game ratings for all players are normalized across each specific position, giving the mean score of 0.0 and SD of 0.5 per position.

- Statistical analyses: Univariate and multivariate binary logistic regression models were used to assess the influence of variables on change in PFF score.
- Performance was measured using the DYAR metric developed by Football Outsiders.

- Concussions and control injuries were determined from weekly NFL injury reports.

- Other variables collected included: none.

- DYAR estimates an individual player's contribution to the team's success. DYAR compares each play only with plays of similar circumstances, adjusts for game situation, and quality of opponent, allows for players of different positions to be compared, and takes into account the number of plays a given player contributes to the game.

- Statistical analyses: Multilevel linear-regression models were used to predict weekly DYAR while allowing for a fixed player-level intercept. Relationships between concussion and DYAR were reported with regression coefficients.
Study 3-Kuhn et al ${ }^{6}$

Cohort study

- NHL players from 2008-2009 to 2014-2015.

- Inclusion criteria: players with a reported concussion as listed on injury reports, players who missed games due to noninjury-related personal reasons were designated as controls, players with at least 5 games played before and after game of concussion or noninjury absence (game of analysis).

- Exclusion criteria: players with concussion or noninjury absence in the preseason, any additional concussions or noninjury absences after the first for the season, players with missed games due to suspension, all goalies, players with both sustained concussion and noninjury absence, players with other sustained injury within $10 \mathrm{~d}$ of game of analysis, players with games analyzed that crossed seasons, players with less than 5 games played before or after game of analysis, and players with missed games within 5 games after the game of analysis due to unknown reasons.

- A total of 94 concussed players and 58 controls met the inclusion and exclusion criteria.

- Performance and style of play were measured using: goals, assists, points, plus-minus, shots, penalty minutes, blocked shots, hits, giveaways, and time on ice.

- Concussions and noninjury absences were determined by injury reports from the Sports Forecaster database within the secondary news source "The Hockey News."

- Other variables collected included: age, position played, NHL experience, games missed, concussion history and team win percentage.

- BMI for each player was calculated according to the most recent information.

- Performance was operationally defined with the statistics for goals, assists, points, plusminus, and shots. Style of play was defined with the statistics for penalty minutes, blocked shots, hits, giveaways, and time on ice. The demographic variables were reported as means and SDs or proportions and percentages. The summed 5-game performance and style of play statistics were calculated as means and SDs.

- Statistical analyses:

Generalized linear modeling, including Poisson/linear regression, was used to determine if differences existed between groups for each variable or between the concussion and noninjury absence groups for a single variable. 
Table 2 (continued)

\begin{tabular}{|c|c|c|c|}
\hline & Study $1-$ Kumar et $\mathrm{al}^{4}$ & Study 2 -Reams et al ${ }^{5}$ & Study $3-$ Kuhn et al $^{6}$ \\
\hline Main findings & $\begin{array}{l}\text { - There was no difference in player } \\
\text { performance after concussion } \\
\text { between players who returned } \\
\text { without missing a game and players } \\
\text { missing at least } 1 \text { game before } \\
\text { return. } \\
\text { - Mean PFF scores before and after } \\
\text { injury were not statistically } \\
\text { different for players returning } \\
\text { within } 7 \mathrm{~d}(0.16 \text { vs } 0.33 \text {, } \\
P=.13) \text { or players missing at least } 1 \\
\text { game ( }-0.06 \text { vs } 0.10, P=.22) \text {. } \\
\text { - None of the tested cofounding } \\
\text { variables had a significant effect } \\
\text { on performance. }\end{array}$ & $\begin{array}{l}\text { - There was no decline in } \\
\text { performance for NFL players with } \\
\text { disclosed concussions after they } \\
\text { returned to play. } \\
\text { - Data were available for } 7.4 \text { (9.6) } \\
\text { plays per game per player and the } \\
\text { primary outcome variable. DYAR } \\
\text { was relatively normally distributed } \\
\text { with a mean of } 6.1 \text { (32). There was } \\
\text { no difference in number of games } \\
\text { missed between concussed players } \\
\text { and controls (1.2 [2.7] vs } 2.0 \text { [3.7]). } \\
\text { Players returning to play the same } \\
\text { week as injury listed on the injury } \\
\text { report showed no significant } \\
\text { change in DYAR (4.2; } 95 \% \text { CI: } \\
-2.6 \text { to } 10.9) \text {. In addition, DYAR } \\
\text { after returning to play at least } 1 \text { wk } \\
\text { after injury showed no significant } \\
\text { difference in performance. } \\
\text { However, players showed } \\
\text { significantly lower DYAR in both } \\
2 \text { wk before disclosed concussion } \\
\text { (-7.12; } 95 \% \text { CI: }-13.0,-1.31 \text { ) and } \\
1 \text { wk before disclosed concussion } \\
\text { (-12.2; } 95 \% \text { CI: }-17.9 \text { to }-6.5 \text { ) on } \\
\text { the injury report. }\end{array}$ & $\begin{array}{l}\text { - Concussion and control groups did not differ } \\
\text { across performance or style of play statistics } \\
\text { after returning from a concussion or } \\
\text { noninjury absence. } \\
\text { - No linear models showed statistically } \\
\text { significant differences between concussion } \\
\text { and control groups across each outcome. } \\
\text { However, differences were noted among } \\
\text { the summed } 5 \text { game totals. } \\
\text { - Over the } 5 \text { game summed totals, players } \\
\text { returning from concussion displayed } \\
\text { negative change statistics in shots }(0.11 \\
\text { [4.4]), penalty minutes }(0.37 \text { [5.4]), and } \\
\text { time on ice (s) (108.3 [691.2]). Players } \\
\text { returning for noninjury absence displayed a } \\
\text { greater number of negative change statistics, } \\
\text { including goals }(0.10 \text { [1.4]), assists }(0.26 \\
\text { [1.7]), points }(0.36[2.3]) \text {, plus-minus }(0.22 \\
\text { [3.5]), shots }(1.1 \text { [6.5]), time on ice (s) } \\
\text { (141.7 [679.6]), and giveaways }(0.19 \text { [2.5]). }\end{array}$ \\
\hline Level of evidence & 3 & 3 & 3 \\
\hline Validity score & N/A & N/A & N/A \\
\hline Conclusion & $\begin{array}{l}\text { - There was no difference found } \\
\text { in NFL player performance upon } \\
\text { return to play from concussion. } \\
\text { There was also no difference in } \\
\text { performance depending on whether } \\
\text { players missed any games or not. } \\
\text { - This article suggests that NFL } \\
\text { players and teams are properly } \\
\text { evaluating concussive injuries } \\
\text { before allowing players to return } \\
\text { to play. }\end{array}$ & $\begin{array}{l}\text { - NFL skill position players returned } \\
\text { to baseline performance levels } \\
\text { upon return to play from } \\
\text { concussion. There was a decline in } \\
\text { performance noted } 1 \text { and } 2 \text { wk } \\
\text { before a diagnosed concussion and } \\
\text { appearing on the injury report. } \\
\text { - This article suggests that players are } \\
\text { recovering from concussion } \\
\text { before returning to play. The } \\
\text { decline in performance before } \\
\text { diagnosed concussion also } \\
\text { suggests that there may be a way } \\
\text { to determine those at a higher risk } \\
\text { of sustaining a concussion in the } \\
\text { short term. It is also possible that } \\
\text { these athletes continued to } \\
\text { participate despite experiencing } \\
\text { concussion-related symptoms } \\
\text { prior to being removed from play. }\end{array}$ & $\begin{array}{l}\text { - There was no difference found in the } \\
\text { performance or style of play of NHL players } \\
\text { upon return to play from concussion when } \\
\text { compared with players returning from } \\
\text { a noninjury absence. } \\
\text { - This article suggests that the current system } \\
\text { for concussion management is functioning } \\
\text { when it comes to time off the ice and } \\
\text { preparing to return to play. }\end{array}$ \\
\hline
\end{tabular}

Abbreviations: BMI, body mass index; CI, confidence interval; DYAR, defense-adjusted yards against replacement; N/A, not applicable; NFL, National Football League; NHL, National Hockey League; PFF, ProFootballFocus.

concussion may (or may not) have caused. Other performance metrics may yield results that show differences in performance; therefore, more research needs to be done in this area.

Most of the literature regarding the effects of concussion in professional sports is focused on neuropsychological and neurocognitive measures. ${ }^{3}$ Studies investigating the effects of concussion on physical performance are very limited in current research; however, 1 link is with future injury risk. Recent literature in soccer and football has shown a significant increase in the risk of subsequent musculoskeletal injury in athletes who have sustained a concussion. ${ }^{7}$ Despite this being a novel finding, it proves important for further evaluation at all levels of play in all sports. Outside of injury risk, physical performance also hinges on the ability of the individual to contribute in their expected role. This may indicate recovery efficacy in relation to athletic performance (ie, returning to preinjury performance prior to return). This can lead to additional information into shaping sport-specific protocols, which focus on physical, physiological, cognitive, and performance recovery, for the most effective management of concussion injuries during return to play. 
Diagnosing and appropriately managing concussions are extremely important for the safety of athletes; however, it may not always be the priority from the athletes' point of view. In many instances, these athletes rely on playing and performing in their respective games to maintain their jobs and earn a living. Missing games for these athletes can directly affect their income and position on their respective teams, perhaps causing increased stress and financial burden, leading to a reluctance to report symptoms of concussion. ${ }^{8}$ Although many professional leagues have introduced new concussion protocol measures to improve concussion diagnosis, ${ }^{4}$ the lack of self-reporting symptoms is still an issue in professional athletes. ${ }^{9}$ Analyzing the effect of concussion on the performance of these athletes may help teams and their medical staffs in making the correct decisions regarding the most appropriate time to allow an athlete to return to play. If athletes are able to definitively see through these and future studies that performance does not suffer upon return to play, perhaps their efforts to selfreport may increase. It has been shown that delayed reporting of concussion symptoms leads to a higher risk of longer recovery times for athletes who continue playing without reporting. ${ }^{10}$ Therefore, the message can be passed to athletes that reporting now not only will not affect performance upon return but will also decrease the risk of a longer recovery period away from play. In addition, research into performance metrics and concussion is needed to create a more comprehensive literature base, which can then be used to help educate and inform athletes about the importance and benefit of reporting symptoms regardless of the situation.

Further research should be focused on other methods to better evaluate the effect of concussions on performance and duration of time out due to injury, including using different metrics for performance and focusing on athletes of sports and levels. Concussions are problematic to all types of sports at all age levels; therefore, research should not be solely focused on professional athletes of collision sports.

This critically appraised topic should be reviewed in 2 years or when additional supporting literature becomes available to ensure the integrity of its findings.

\section{Acknowledgment}

The authorship team has no conflicts of interest to disclose.

\section{References}

1. Nathanson JT, Connolly JG, Yuk F, et al. Concussion incidence in professional football: position-specific analysis with use of a novel metric. Orthop J Sports Med. 2016;27(4):2325967115622621. PubMed ID: 26848481 doi:10.1177/2325967115622621

2. Ruhe A, Gansslen A, Klein W. The incidence of concussion in professional and collegiate ice hockey: are we making progress? A systematic review of the literature. Br J Sports Med. 2014;48: 102-106. PubMed ID: 23645831 doi:10.1136/bjsports-2012-091609

3. Broglio SP, Cantu RC, Gioia GA, et al. National Athletic Trainers' Association position statement: management of sport concussion. J Athl Train. 2014;49(2):245-265. PubMed ID: 24601910 doi:10. 4085/1062-6050-49.1.07

4. Kumar NS, Chin M, O’Neill C, Jakoi AM, Tabb L, Wolf M. On-field performance of National Football League players after return from concussion. Am J Sports Med. 2014;42(9):2050-2055. PubMed ID: 25008256 doi:10.1177/0363546514539449

5. Reams N, Hayward RA, Kutcher JS, Burke JF. Effect of concussion on performance of National Football League players. Int J Sports Physiol. 2017;12(8):1100-1104. PubMed ID: 28095082 doi:10. 1123/ijspp.2016-0508

6. Kuhn AW, Zuckerman SL, Totten D, Solomon GS. Performance and style of play after returning from concussion in the National Hockey League. Am J Sports Med. 2016;44(8):2152-2157. PubMed ID: 27159319 doi: $10.1177 / 0363546516638327$

7. https://www.cebm.net/wp-content/uploads/2014/06/CEBM-Levelsof-Evidence-2.1.pdf

8. Pietrosimone B, Golightly YM, Mihalik JP, Guskiewicz KM. Concussion frequency associates with musculoskeletal injury in retired NFL players. Med Sci Sport Exer. 2015;47(11):2366-2372. PubMed ID: 25871466 doi:10.1249/MSS.0000000000000684

9. Donaldson L, Li B, Cusimano MD. Economic burden of time lost due to injury in NHL hockey players. Inj Prev. 2014;20(5):347-349. PubMed ID: 24446078 doi:10.1136/injuryprev-2013-041016

10. Associated Press. Players still willing to hide head injuries. December 26, 2011. http://espn.go.com/nfl/story/_/id/7388074/nfl-playerssayhiding-concussions-option

11. Asken BM, McCrea MA, Clugston JR, Snyder AR, Houck ZM, Bauer RM. "Playing through it": delayed reporting and removal from athletic activity after concussion predicts prolonged recovery. $J$ Athl Train. 2016;51(4):329-335. PubMed ID: 27111584 doi:10.4085/ 1062-6050-51.5.02 